\title{
ACOUSTIC EMISSION ENERGY TO \\ PULSE HEIGHT CONVERTER
}

B. W. Speller

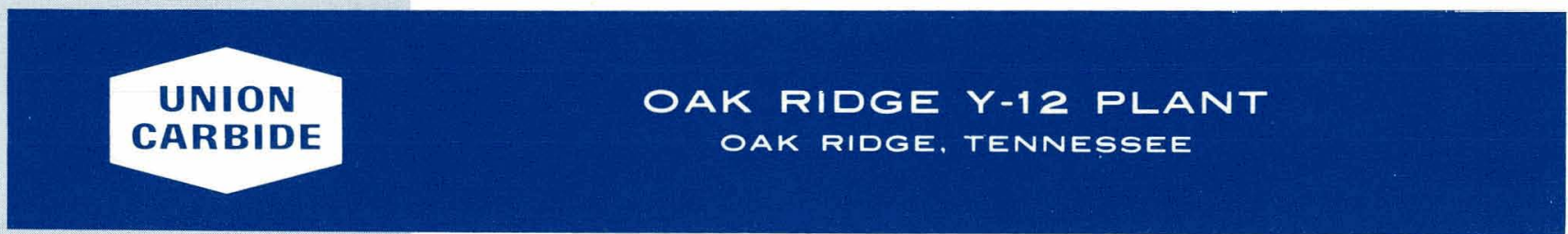

prepared for the U.S. ATOMIC ENERGY COMMISSION

under U.S. GOVERNMENT Contract W.7405 eng 26

\section{MASTER}




\section{DISCLAIMER}

This report was prepared as an account of work sponsored by an agency of the United States Government. Neither the United States Government nor any agency Thereof, nor any of their employees, makes any warranty, express or implied, or assumes any legal liability or responsibility for the accuracy, completeness, or usefulness of any information, apparatus, product, or process disclosed, or represents that its use would not infringe privately owned rights. Reference herein to any specific commercial product, process, or service by trade name, trademark, manufacturer, or otherwise does not necessarily constitute or imply its endorsement, recommendation, or favoring by the United States Government or any agency thereof. The views and opinions of authors expressed herein do not necessarily state or reflect those of the United States Government or any agency thereof. 


\section{DISCLAIMER}

Portions of this document may be illegible in electronic image products. Images are produced from the best available original document. 


\section{Printed in the United States of America. Available from National Technical Information Service}

U.S. Department of Commerce

5285 Port Royal Road, Springfield, Virginia 22151

Price: Printed Copy \$4.00; Microfiche $\$ 0.95$

This report was prepared as an account of work sponsored by the United States Government. Neither the United States nor the United States Atomic Energy Commission, nor any of their employees, nor any of their contractors, subcontractors, or their employees, makes any warranty, express or implied, or assumes any legal liability or responsibility for the accuracy, completeness or usefulness of any information, apparatus, product or process disclosed, or represents that its use would not infringe privately owned rights. 


\section{ACOUSTIC EMISSION ENERGY TO PULSE HEIGHT CONVERTER}

B. W. Speller

Oak Ridge Y-12 Plant

P.O. Box Y, Oak Ridge, Tennessee 37830

Date Issued - December 18, 1973

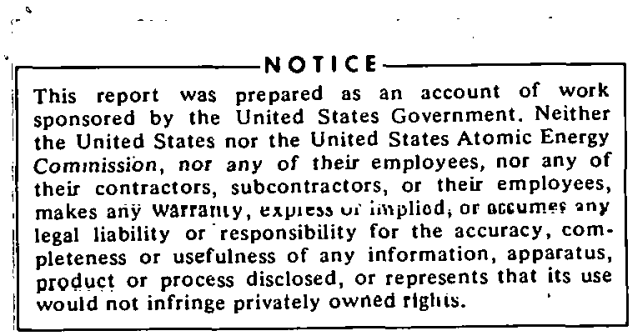

Prepared tor the U.S. Atomic Eneryv Cuminisision Under U.S. Government Contract W-7405eng-26 


\begin{abstract}
An energy-to-pulse-height converter was developed for use in acoustic emission testing. This instrument accepts an amplified signal from a piezoelectric crystal and generates a pulse whose amplitude is proportional to either the energy or width of the input signal. Either linear or logarithmic responses can be selected. Theory, circuit design, and performance specifications have been determined, based on calculations and measurements.
\end{abstract}


CONTENTS

SUMMARY $\ldots \ldots \ldots \ldots \ldots \ldots \ldots \ldots \ldots \ldots$

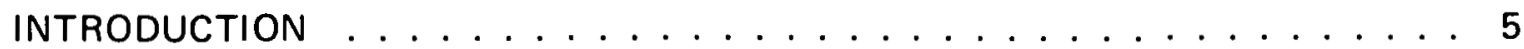

ACOUSTIC EMISSION ENERGY TO PULSE HEIGHT CONVERTER . . . . . . . . 6

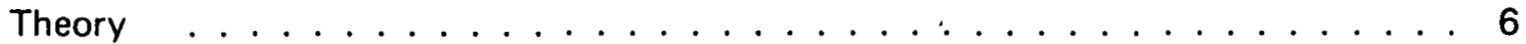

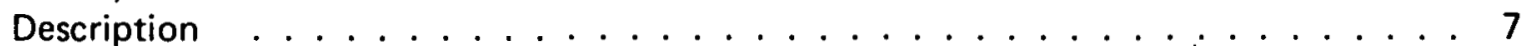

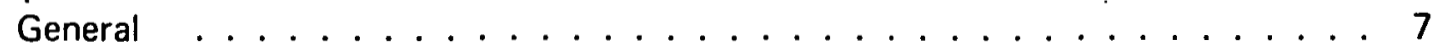

Widli Delectur . . . . . . . . . . . . . . . . . . 8

Signal Converter Module $\ldots \ldots \ldots \ldots \ldots$

System Limitations $\ldots \ldots \ldots \ldots \ldots \ldots$

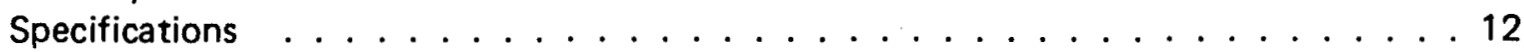

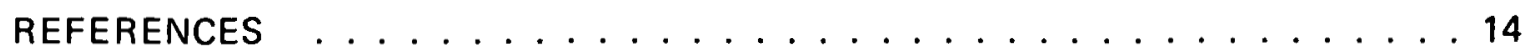

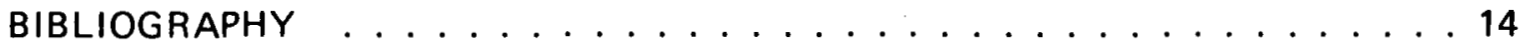

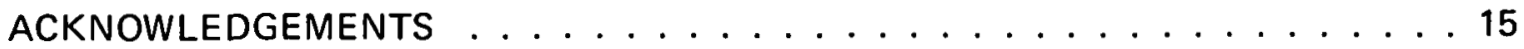




\section{SUMMARY}

An energy-to-pulse-height converter was developed for use in acoustic emission testing. The instrument consists primarily of state-of-the-art operational amplifiers and function devices which are housed in two single-width NIM (nuclear instrument module) modules. It will accept amplified signals from a piezoelectric crystal and generate pulses with amplitudes proportional to the energy, log energy, width, or log width of the input signals. These pulses can then be analyzed by the use of commercially available single or multichannel analyzers and counters. It was designed for use primarily in the 100 to $600-\mathrm{kHz}$ frequency range, but will operate above $1 \mathrm{MHz}$ with degraded performance. Possible applications include material-failure-mode analysis and powder-particle-size measurements. 


\section{INTRODUCTION}

Acoustic emission testing ( $A E T$ ) involves monitoring the release of vibrational mechanical energy in materials under stress. Typically, a piezoelectric transducer is attached to the test material to convert the mechanical vibrations into electrical signals. These signals are then amplified and analyzed. The technique most used in the past for analyzing these signals was to determine the rate of emission of signals which produced a voltage above a predetermined level.

Development work in AET was begun at the Oak Ridge Y-12 Plant (a) in the late 1960s. Applications of AET include: predicting ultimate strength of vessels, measuring powder flow rates, and for feedbacks in adaptive arc welding. (1) AET is being considered for other applications, such as defining failure modes of materials and determining powder particle sizes.

Recently, more attention has been given to measuring the energy, rather than amplitude, of the signals. It is felt that the energy of the signal would be indicative of the mode of failure (ie, fiber breaking or cracking) that generated it and possibly other factors that amplitude alone would not. Beattie and Jaramillo at Sandia-Albuquerque developed a circuit for measuring the energy of randomly occurring bursts of rf signals. (2) Their circuit does not, however, measure the energy of each burst individually, but produces a pulse train with a frequency proportional to the total signal energy. An energy analyzer, to measure the energy of each emission independent of the others, was needed for further development in this area. 


\section{ACOUSTIC EMISSION ENERGY TO PULSE HEIGHT CONVERTER}

\section{THEORY}

Energy is the capacity for doing work, and the unit of measurement is the joule (J). The energy in an electrical signal can be determined by integrating the power for the period of interest (eg, signal duration). Power input to a circuit is defined as:

$$
\frac{e_{i n}^{2}}{z_{i n}}
$$

where:

$e_{\text {in }}$ represents the input voltage in volts, and

$Z_{\text {in }}$ the input impedance of the circuit in ohms.

Integrating this signal for its duration gives:

$$
E=\int_{0}^{t_{1}} \frac{\dot{e}_{i n}^{2}}{Z_{\text {in }}} d t,
$$

where:

E represents the energy in joules, and

$\tau_{1}$ the signal duration in seconds.

Since $Z_{\text {in }}$ can be made fairly constant over the frequency range of interest, it can be factored out; and, if energy distribution (relative energies) is of primary importance, it can even be ignored.

From Equation 2, it can be seen that an energy-to-pulse-height converter is required to perform four major functions: (1) determine the duration of the signal, (2) square the input voltage signal, (3) integrate the squared input for the duration of the signal, and (4) generate a pulse whose amplitude is proportional to energy or width. These four functions can be realized by using state-of-the-art function devices. A signal proportional to signal duration can be obtained by integrating a constant voltage:

$$
e_{0}=K \int_{0}^{t} e_{D C} d t=K e_{D C} t_{1}
$$

where:

$e_{0}$ represents the integrator output,

$t_{1}$ the duration of the signal, and 
eDC a constant reference voltage.

$K \quad$ is the constant of integration.

Squaring can be accomplished with a commercially available multiplier module with a transfer function of:

$$
e_{0}=\frac{e_{x} e_{y}}{10}
$$

where:

$$
\begin{aligned}
& e_{0} \text { represents the output voltage of the multiplier in volts, and } \\
& e_{x} \text { and } e_{y} \text { the input voltages in volts. }
\end{aligned}
$$

The multiplier can also be used to produce an output pulse of precise width by using the integrator output as one input and a uniform pulse as the other. This approach is the one to be taken in this report.

\section{DESCRIPTION}

\section{General}

A block diagram of a typical acoustic emission test setup employing the energy-to-pulse converter is given in Figure 1. The piezoelectric transducer is physically attached to the material under test. Its output signal is amplified before entering the energy converter. The converter analyzes its input signals and generates pulses which are compatible with commercially available multichannel analyzers (MCA) and counters. In the MCA, the amplitude of each input pulse is measured, and one count is added to the memory location corresponding to that amplitude. At the end of the test, a display of the number of pulses versus the pulse amplitude can be obtained on a cathode-ray tube, an $x-y$ recorder, a teletypewriter, or some other suitable readout device.

Each time energy is released in the material, the mechanical vibration travels through the material and strikes the surface of the transducer which converts this mechanical motion into an electrical signal. The exact shape and size of the signal depends on many parameters, namely: size and shape of the material, coupling between the material and transducer, the type of transducer, and of course the magnitude, location, and type of energy release. In general, the signal will he in the form of a short-duration, damped sine wave. $(3,4)$ The frequency of the sine wave will be determined by the transducer and can vary from approximately $100 \mathrm{kHz}$ to several $\mathrm{MHz}$. The time between bursts is random and can vary from microseconds to seconds or minutes.

The energy converter developed for use with this type of signal consists of two NIM plug-in modules-a width detector and a signal converter (Figure 2). The width detector determines 
the duration of the input signals and generates pulses which are used by the converter module to convert signal energy or width into pulses acceptable to an MCA or counter.

\section{Width Detector}

The width detector module consists of three sections-a peak detector, comparator, and pulseshaping logic (see Figure 3). In general, the width of the signal is defined as the time duration that the amplitude of the signal envelope is above a preset level.

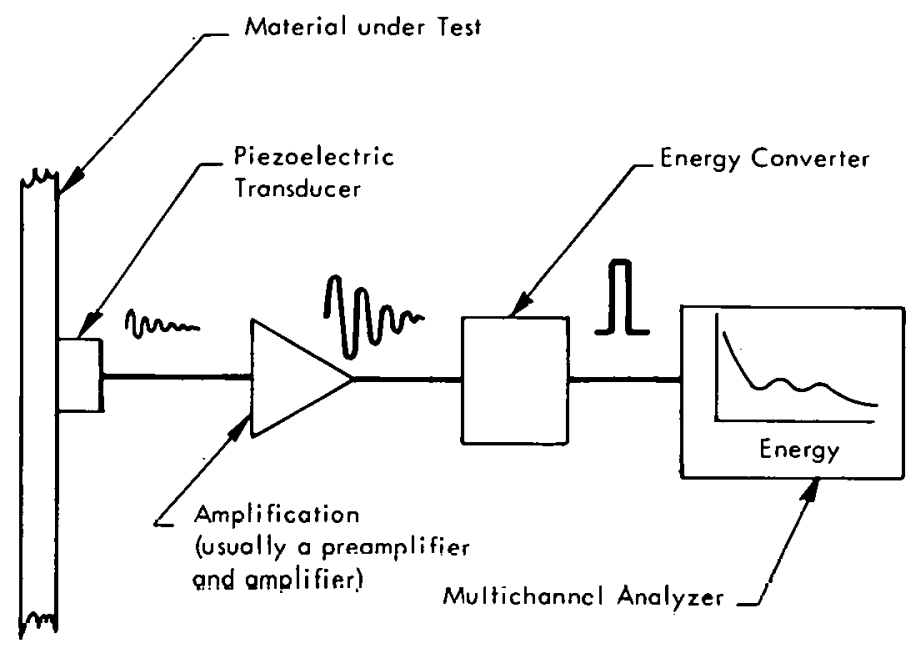

Figure 1. A TYPICAL ACOUSTIC EMISSION TESST ARRANGEMENTï.

Salient features of the peak detector are a fast rise time and a slow fall time. For the circuit used, the rise time ( $0-10$ volts) is approximately 0.25 microsecond. Fall time is front-panel selectable and is determined by the values of the resistor and capacitor. Four time-constant values are provided and were selected on the basis of observations of simulated and actual test data.

The peak-detector output (signal envelope) is compared with a preset threshold voltage using a high-speed comparator. When the amplitude of the signal envelope exceeds that of the threshold, the comparator output changes from a high to a low level and stays there until the envelope falls back below the threshold (Figure 4). Hysteresis of the comparator is approximately $U .08$ volt.

Finally, the comparator output is shaped in the logic section where two signals (signal duration and end of signal) are generated for use in the converter module. Provision is made to disable the outputs for a predetermined time after each pulse. Signals that begin during this time are disregarded in order to allow the converter module to reset.

\section{Signal Converter Module}

As shown in Figure 5, function modules are interconnected to generate the functions given by Equations 2 and 3 . The heart of the module is the integrator which integrates only while the field effect transistor (FET) is turned off.

In the energy mode, the input acoustic emission signal is squared and then integrated for the duration of the signal. To determine signal width, the input to the integrator is switched to a dc voltage. The integrator output is buffered through a selector switch into an inverting amplifier or a log converter module. The signal is then multiplied by a uniform end-of-signal pulse in the output multiplier to generate a uniform width pulse whose amplitude is proportional to energy, width, or log of energy or width. Means are provided in the buffer amplifier for compressing and offsetting the signals so that very small and very large signals will fall in the range of the multichannel analyzer. 


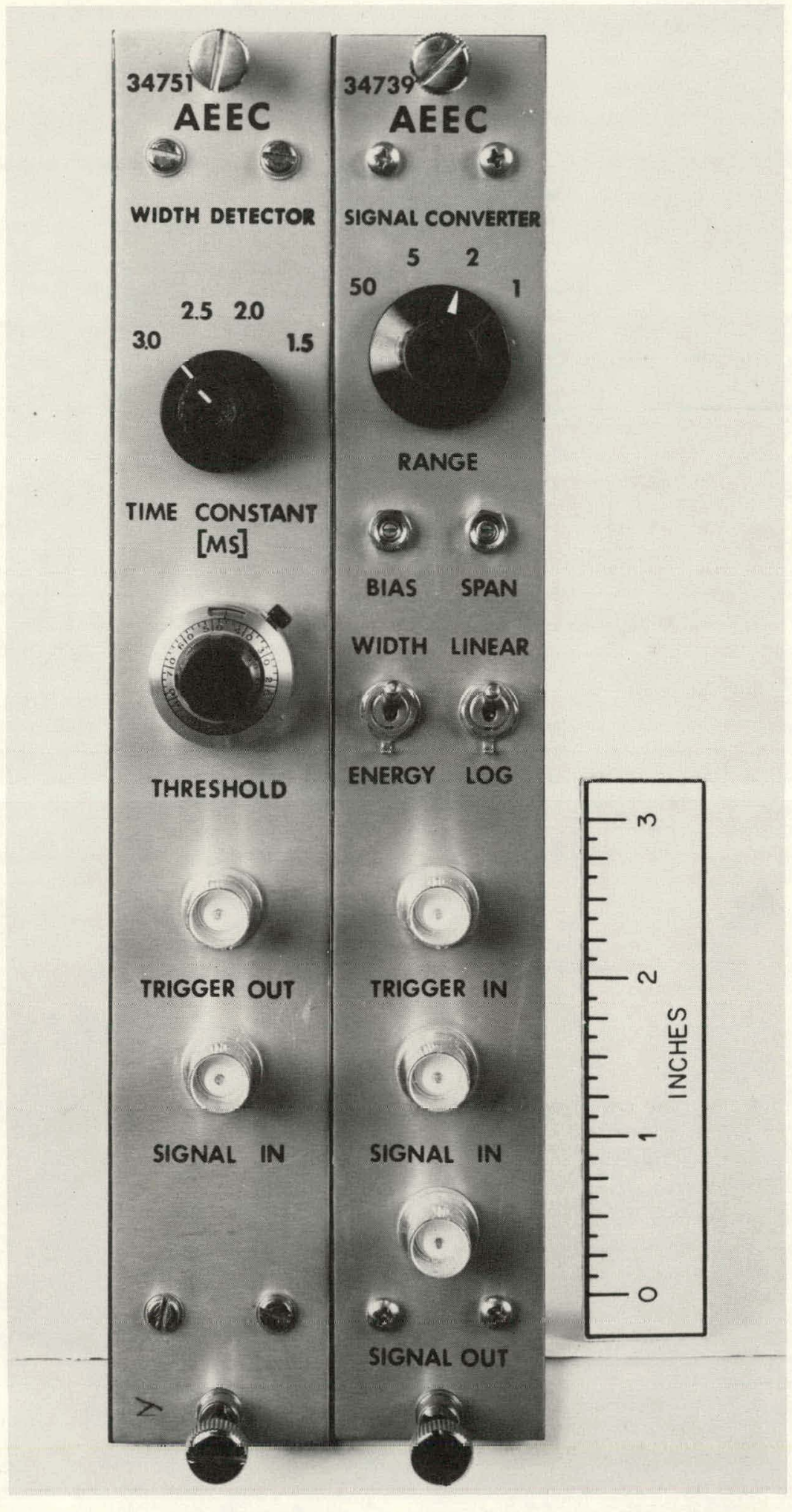

151126

Figure 2. FRONT PANELS OF THE WIDTH DETECTOR AND SIGNAL CONVERTER MODULES. 


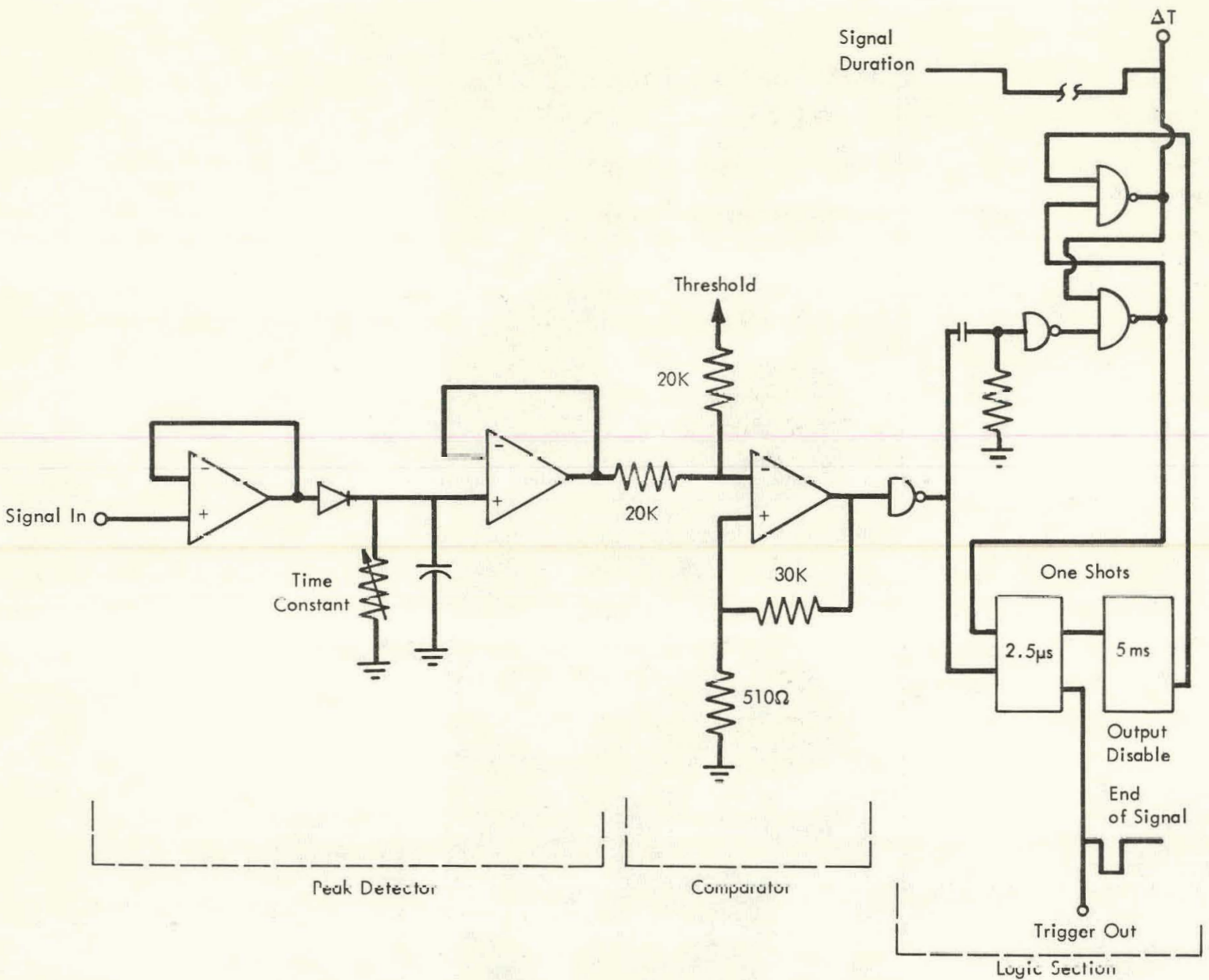

Figure 3. WIDTH DETECTOR MODULE. (Partial Diagram)

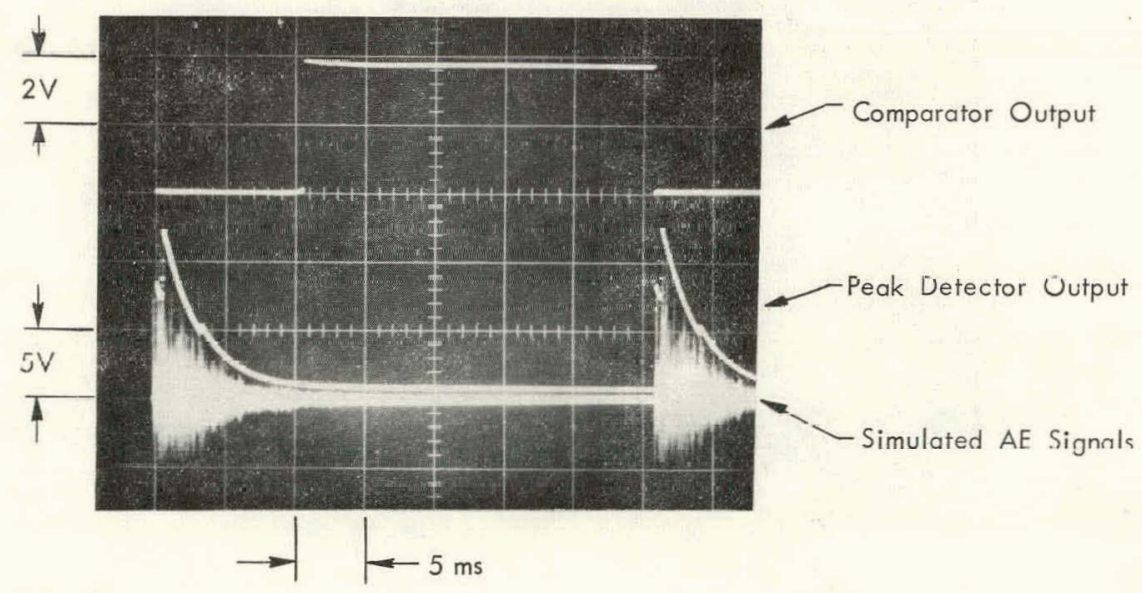

Figure 4. OSCILLOSCOPE DISPLAY OF SIMULATED ACOUSTIC EMISSION SIGNALS AND THE CORRESPONDING PEAK DETECTOR AND COMPARATOR RESPONSES. 


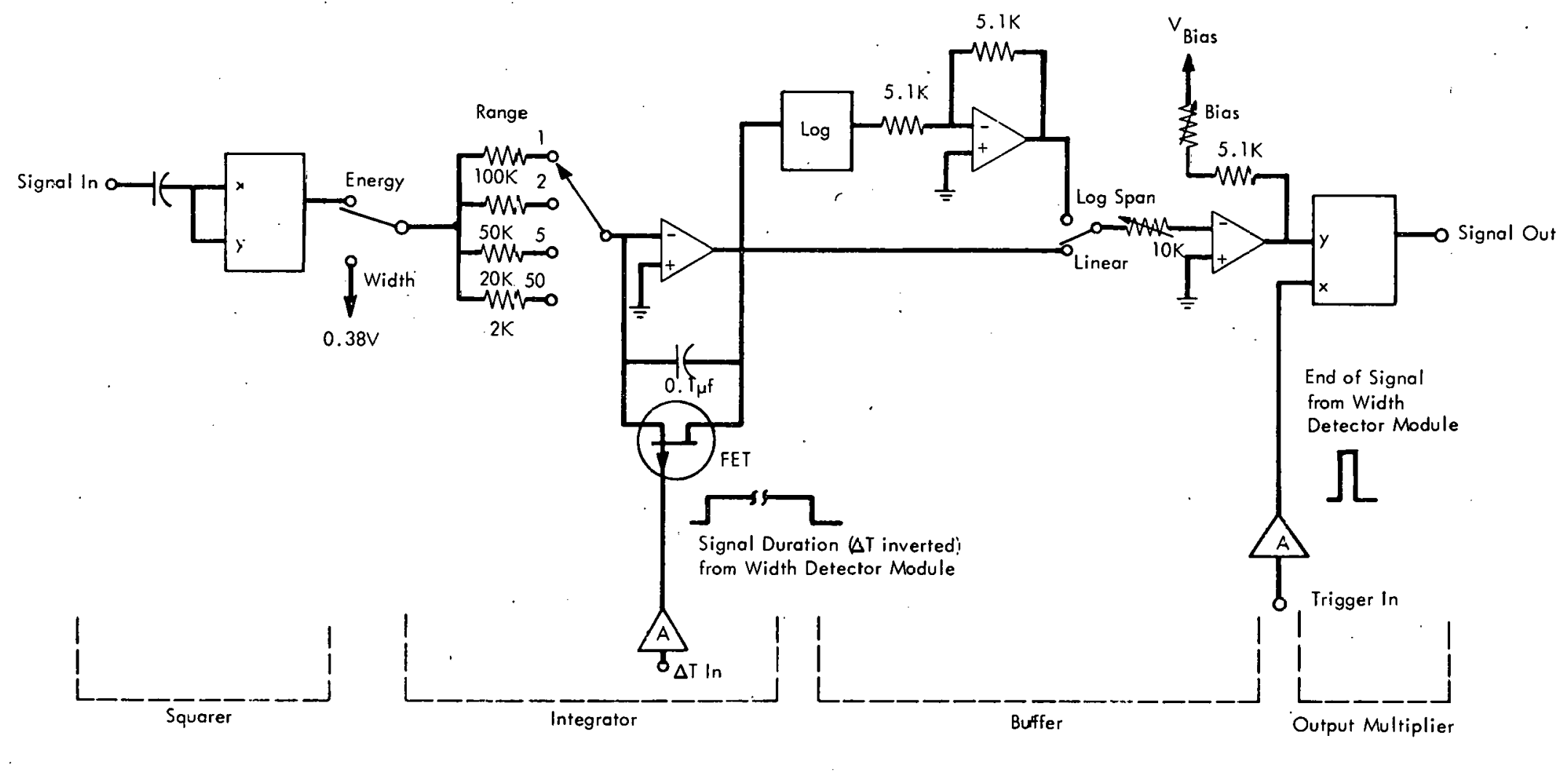

Figure 5. SIGNAL CONVERTER MODULE. (Partial Dagram) 


\section{System Limitations}

The primary sources of limitations are due to the active components. The major limitations in the width detector module occur in the peak detector circuit. First, the high-pass input filter is designed to block out low-frequency signals. It gives 10 percent attenuation at about $8 \mathrm{kHz}$ and 50 percent at about $1.5 \mathrm{kHz}$. Limits for the high-frequency end are determined by the "op amp" characteristics. With a guaranteed and typical output current of 10 and 20 ma, respectively, the op amp can charge the peak-storage capacitor at frequencies up to 300 $\mathrm{kHz}$, or $600 \mathrm{kHz}$ without attenuation for a full-scale 10-volt input. Finally, the forward voltage drop of the diode is subtracted from the signal which has the effect of reducing the measured signal duration. By using a bias, the diode drop is limited to 0.4 volt. Reduction in the measured duration for a signal of peak amplitude, $\mathrm{e}_{\mathrm{j}}$, and a threshold setting of $\mathrm{e}_{\mathrm{T}}$ can be calculated using the following equation:

$$
\text { Reduction in Duration }=1-\frac{\ln \frac{\mathrm{e}_{\mathrm{S}}-0.4}{\mathrm{e}_{\mathrm{T}}}}{\ln \frac{\mathrm{e}_{\mathrm{S}}}{\mathrm{e}_{\mathrm{T}}}} \text {. }
$$

Similarly, the sources of limitations in the converter module are due to the active components. After trimming the circuits, the power supply voltages, reference voltages, and multiplier output were monitored for several hours in a standard laboratory environment 4 $2.5^{\circ} \mathrm{C}$ ). Drift in these variables was found to be in the order of 0.1 percent. The input high-pass filter gave 10 percent attenuation at approximately $10 \mathrm{kHz}$ and 50 percent at approximately $2 \mathrm{kHz}$.

Primary limitations in the input multiplier are due to its nonlinearity and phase shifts at higher frequencies. Errors in the multiplier output were observed to be less than 1 percent up to $600 \mathrm{kHz}$ and $b$ percent at $1 \mathrm{MHz}$ for a 20-volt peak-to-peak sine wave.

In the integrator, the primary limitation is due to the resistance of the FET when it is switched on (no signal). For the type FET used, annrnximately 0.18 volt is rcalized at the output for 1 volt input on the most sensitive range. Thus, if the width detector threshuld is set to 1 volt, the integrator output will begin at 0.18 volt. This action is equivalent tn adding a bias to the data. Un the less sensitive ranges, the effect is proportionately reduced.

\section{SPECIFICATIONS}

Because of the many variables involved, a thorough evaluation of every possible parameter would be prohibitively time consuming and expensive. Therefore, the specifications to follow are based on a combination of observations, manufacturers' specifications, and calculations. 
Input Impedance

Input Voltage

Power Requirements ${ }^{(1)}$

Peak Detector Decay Time Constants ${ }^{(1)}$

Threshold Voltage ${ }^{(1)}$

Linearity

Outputs - TTL Levels (2)

Signal Duration

High Level

Low Level

End of Signal

High Level

Low Level Width ${ }^{(1)}$

Operating Temperature (2)

Dimensions ( $L \times W \times H$ overall)
$0.022 \mu \mathrm{f}$ in series with $2 \mathrm{k}$

$$
\pm 10 \mathrm{v}
$$

$\pm 24 \mathrm{vdc}$ at $125 \mathrm{ma}$ $12 \mathrm{vdc}$ at $100 \mathrm{ma}$

-12 vdc at $125 \mathrm{ma}$

$1.5,2.0,2.5$, and $3.0 \mathrm{~ms}$

$0.10 v, \pm 5 \%$

$0.2 \%$

(1) Verified by tests.

(2) Calculated or based on manufacturers' specifications.
$2.4 v \min , 400 \mu \mathrm{a}$ $0.4 v$ at $-16 \mathrm{~mA}(\mathrm{max})$

$2.4 \vee \min , 800 \mu \mathrm{A}$ $0.8 v$ at -16 ma $(\max )$ $2.5 \pm 0.5 \mu \mathrm{s}$ $0.70^{\circ} \mathrm{C}$
Input Impedance

Input Voltage (1)

Power Requirements (2)

Output

Ranges

Energy (1)

Width $(2)$

Oulisut Diag(2)

Output Span (2)

Output Impedance (1)

Output Signal (1)
$0.0068 \mu \mathrm{f}$ in serips with $5 \mathrm{k}$

$\pm 10 \mathrm{v}$

$\pm 24 \mathrm{vdc}$ at $125 \mathrm{ma}$

Energy, Width, Log Energy, Log Width

5
10
62.6

50

1 J

139.5

62.6

5.26

ms

$0 \cdot 0.5 v$

$6-10 \vee(\max )$

$350 \Omega$

$0-10 v, 10 \mathrm{ma}(\max ), 2.5 \mu \mathrm{s}$ wide

(1) Calculated or based on manufacturers' specifications.

(2) Verified by tests. 


\section{REFERENCES}

(1) Adaptive Spot Weld Control System, manufactured by Trodyne Corporation,Teterbow, New Jersey.

(2) Beattie, A. G. and Jaramillo, R. A.; The Measurement of Energy in Acoustic Emission; Sandia Laboratories, Albuquerque, New Mexico (1972). (Draft of an article sent to Review of Scientific Instruments for publication.)

(3) Redwood, M.; "Transient Performance of a Piezoelectric Transducer", The Journal of the Acoustical Society of America, 33,(4): April 1961.

(4) Cook, E. G.; "Transient and Steady-State Response of Ultrasunic Plezoelectric Transducers", IRE Convention Recurd, Part 9; 1956 INational Convention.

\section{BIBLIOGRAPHY}

Tobey, Gene E., Graeme, Jerald G., and Huelsman, Lawrence P., editors; Operational Amplifiers: Design and Applications; McGraw-Hill (1971). 


\section{ACKNOWLEDGEMENTS}

The author wishes to express his appreciation to the following for their contributions to the project: J. G. Kimack and. D. A. Rickard for their design suggestions and for performing the laboratory checkouts; H.W. Blake for his encouragement and suggestions, and especially for the financial support; and, also, S. A. Wallace for his helpful discussions on acoustic emission testing. 


\section{DISTRIBUTION}

Atomic Energy Commission - ALO

Vespe, V. C.

Atomic Energy Commission - ORO

Hickman, H. D.

Zachry, D. S., Jr

Dow - Rocky Flats

Lott, L. A.

\section{Lawrence Livermore Laboratory}

Chiao, T. T.

Hametad, M. A.

Liptai, R. G.

McFarland, G. C.

Tatro, C. A.

Technical Information Division

Los Alamos Scientific Laboratory

Baker, R. D.

Briscoe, W. L.

Elliott, D. E.

Oak Ridge Gaseous Diffusion Plant

Barton, J. C.

Blake, H. W.

Keyser, R. M.

Wilcox, W. J., Jr

Winkel, R. A.

\section{Oak Ridge National Laboratory}

Borkowski, C. J.

McClung, R. W.

Oak Ridge Y-12 Plant

Bernander, N. K.

Briscoe, O. W.

Burditt, R. B.
Burkhart, L. E.

Denny, $A$.

Dodson, W. H.

Jackson, V. C.

Jones, F. W.

Kahl, K. G.

Keith, Alvin

Lundin, M. I.

Marrow, G. B.

Mason, D. L.

Mclendon, J. D.

Mitcliel, G. W.

Moyer, M. W.

Noey, J. L.

Schreyer, J. M.

Smith, H. F., Jr

Smith, R. D.

Speller, B. W. (5)

Wallace, S. A.

Weathersby, W. E.

Wright, C. C.

Yaggi, W. J.

Y-12 Central Files (5)

Y-12 Central Files (master copy)

$Y-12$ Files (route)

$Y-12$ Central Files ( $Y-12 R C)$

Paducah Gaseous Diffusion Plant

Levin, R. W.

Sandia $=$ Albuquerque

Ballard, D. W.

Beattie, A. G.

Jaramillo, R. A.

Mail Services Section

\section{Sandia - Livermore}

Baker, A. F.

Library

Murphy, B. F.

In addition, this report is distributed in accordance with the category UC-37, Instruments, as given in the USAEC Standard Distribution Lists for Unclassified Scientific and Technical Reports, TID-4500. 